\title{
INFLUENCE OF THE ADDITION OF PORE FOAMING AGENT ON MECHANICAL AND THERMAL PROPERTIES OF PORCELAIN TILES
}

\author{
PANIDA WIMUKTIWAN, MANA RODCHOM, KANIT SOONGPRASIT, \\ DUANGDUEN ATONG, ${ }^{\#}$ SUPAWAN VICHAPHUND
}

\author{
Ceramics and Construction Materials Research Group, National Metal and Materials Technology Center (MTEC), \\ National Science and Technology Development Agency (NSTDA), \\ Khlong Nueng, Khlong Luang, Pathumthani, 12120, Thailand \\ ${ }^{\#}$ E-mail: supawank@mtec.or.th
}

Submitted April 28, 2019; accepted September 26, 2019

\begin{abstract}
Keywords: Porcelain tile, Porcelain stoneware tile, Porous ceramic, Porosity, Poly methyl methacrylate (PMMA), Mechanical strength (flexural strength, three-point bending), Thermal conductivity

In this work, the effect of pore foaming agents (polymethyl methacrylate, PMMA) on the densification characteristics as well as mechanical and thermal properties of sintered porcelain samples was investigated. The influence of the PMMA content $(0-20 \mathrm{wt} . \%)$ and sintering temperature $\left(1000-1300{ }^{\circ} \mathrm{C}\right)$ were also studied. The result showed that the incorporation of PMMA in porcelain bodies led to a decrease in the density, while the porosity increased with an increase in sintering temperature. At $1300{ }^{\circ} \mathrm{C}$, the bulk density and porosity of porous porcelain samples with PMMA additions $(5-20 \mathrm{wt}$. \%) were in the range of $1.91-2.23 \mathrm{~g} \cdot \mathrm{cm}^{-3}$ and $1.3-17.2 \%$, respectively. The flexural strength of the porous porcelain samples prepared by adding $5-20 \mathrm{wt} \% \mathrm{PMMA}$ and sintering at $1300{ }^{\circ} \mathrm{C}$ was in a range of $36-56 \mathrm{MPa}$, which is higher than the minimum strength values (35 MPa) of ISO 13006 standard for ceramic tiles. The thermal conductivity of porous porcelain is a function of the sintering temperatures. The increase in sintering temperature had a positive effect on the thermal conductivity of ceramic samples, because the thermal conductivity decreased significantly with increasing porosity levels. The addition of $20 \mathrm{wt} . \%$ PMMA in porcelain samples sintered at $1300{ }^{\circ} \mathrm{C}$ reduced the thermal conductivity up to $34 \%$ while maintaining acceptable flexural strength values ( 36 MPa). Thus, it is possible to use these porcelain samples as ceramic tiles in order to enhance the thermal resistance of building materials.
\end{abstract}

\section{INTRODUCTION}

Nowadays, porcelain stoneware tiles have become very popular as these products have high physical and mechanical properties. The ceramic tiles manufactured in the industrial sector are commonly classified according to ISO 13006 [1], which is mainly divided based on water absorption and different strength levels. The classification of floor tiles or wall tiles depends on their usage and their properties. Floor and wall tiles are widely used in buildings and houses, bathrooms, kitchens, swimming pools, laboratory rooms, hospitals and industries.

Several compositions of porcelain stoneware have been reported [2-17]. They commonly consisted of clay $40-75 \%$, feldspar 0 - $18 \%$, and quartz 27 - $50 \%$ [3]. A lot of works have focused on the feasibility of replacing ceramic components by applying alternative raw materials [4, 18], functional ceramic tiles with cleanability or photocatalytic properties [19] and the improvement of thermal property in order to increase the efficiency of construction materials in terms of reducing energy consumption for environmental friendliness $[5,7,20]$. For this purpose, pore forming agents including polymer particles [5, 7], starch [21], carbon black
[22], and biomass $[23,24]$ have been widely studied as they can easily control the pore size as well as create the various porosity levels, leading to a reduction of thermal conductivity. However, only a few works focused on both the mechanical and thermal properties of claybased materials [5, 7, 24]. Among of pore forming agents, starch seems to be an appropriate pore foaming agent because it is a natural biopolymer, with easy handling and processing, good commercial availability relatively low cost. Unfortunately, the pore size range is limited, typically between 5 and 50 micrometers. This limits the application when large pores are desirable [5]. In the case of biomass, irregular and larger pores are usually found in the porous ceramics owing to the agglomeration and nonuniformity of biomass as a poreforming agent, resulting in lower mechanical strength. In addition, some impurities such as $\mathrm{K}_{2} \mathrm{O}, \mathrm{Na}_{2} \mathrm{O}$ and $\mathrm{SiO}_{2}$ may also reduce the mechanical properties of ceramics [22]. Polymer particles are an effective alternative to starch and biomass. They exhibit defect-free burn out at relatively low temperature. Furthermore, they are usually environmentally friendly and also relatively cheap. Additionally, they allow very efficient pore size control and are easily mixed with ceramic powders. These advantages make them economically attractive for industrial applications [5]. 
In this research, polymethyl methacrylate (PMMA) was selected as a pore forming agent to generate porosity in porcelain tiles (which may be considered as a special type of porcelain stoneware tiles), as PMMA is widely used in ceramics since it presents a good balance of thermal properties suitable for the proposed application. PMMA decomposes almost exclusively to its monomer and at a very high and steady state [5]. The aim of this research was to study the influence of pore foaming agents (polymethyl methacrylate, PMMA) on the physical, mechanical and thermal properties of sintered porcelain samples. The contents of PMMA (0 - 20 wt. \%) and sintering temperature $\left(1000-1300{ }^{\circ} \mathrm{C}\right)$ were also studied.

\section{EXPERIMENTAL}

The raw materials used in this investigation were kaolin and potassium feldspar (both from Amarin Ceramics Co., Ltd, Thailand) and quartz (Cernic International Co., Ltd, Thailand). All raw materials had an industrial grain size less than $45 \mu \mathrm{m}$ (mesh 325). The chemical compositions of ceramic raw materials were determined by X-ray fluorescence (XRF; Rigaku ZSX Primus) analysis. Polymethyl methacrylate (PMMA with a density of $1.19 \mathrm{~g} \cdot \mathrm{cm}^{-3}$, obtained from Liack Seng Trading Co., Ltd., Thailand) was used as a pore foaming agent. Prior to the experiment, PMMA particles were ground with a high speed rotor mill (Ultra centrifugal Mill ZM200, Retsch) in order to reduce the particle size from $3-4 \mathrm{~mm}$ to $45-250 \mu \mathrm{m}$.

Table 1. Batch compositions of porcelain samples.

\begin{tabular}{lccccc}
\hline \multirow{2}{*}{ Compositions } & \multicolumn{3}{c}{$\begin{array}{c}\text { Raw materials } \\
\text { (wt. \%) }\end{array}$} & & $\begin{array}{c}\text { Pore forming } \\
\text { agents (wt. \%) }\end{array}$ \\
\cline { 2 - 4 } \cline { 2 - 3 } & kaolin & Quartz & K-feldspar & PMMA \\
\hline P-Blank & 50 & 25 & 25 & & 0 \\
P-PMMA 5 & 50 & 25 & 25 & \\
P-PMMA 10 & 50 & 25 & 25 & \\
P-PMMA 20 & 50 & 25 & 25 & & 10 \\
\hline
\end{tabular}

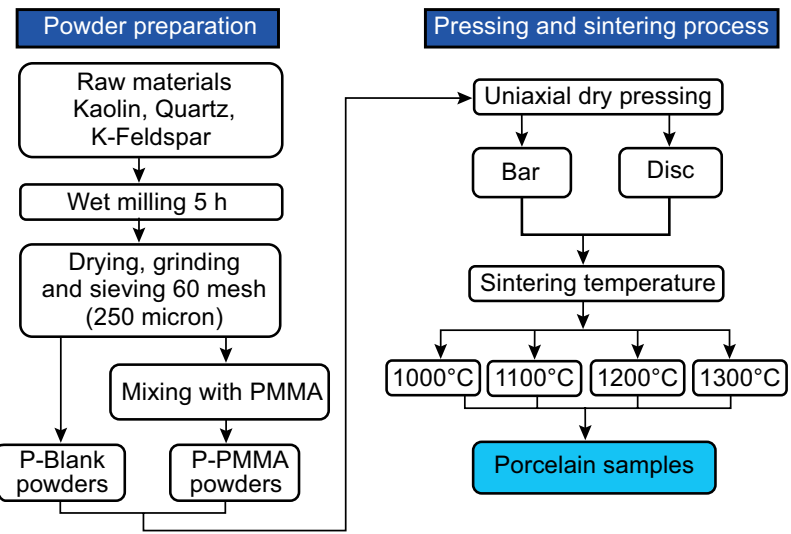

Figure 1. Schematic diagram of experimental procedure.
Initially, a porcelain composition was prepared by mixing 50 wt. $\%$ kaolin, 25 wt. \% quartz and 25 wt. $\%$ potassium feldspar by conventional ball milling with distilled water for $5 \mathrm{~h}$. The slurry was dried at $100{ }^{\circ} \mathrm{C}$ for $24 \mathrm{~h}$ and ground in a porcelain mortar. The mixed powder then passed through a 60 -mesh screen $(250 \mu \mathrm{m})$. In order to fabricate the porous porcelain, body mixes were formulated by adding various amounts of pore foaming agent (polymethyl methacrylate, PMMA) with a size of $45-250$ microns on the proportion to 0 (P-Blank), 5 (P-PMMA 5), 10 (P-PMMA 10), and 20 wt. \% (P-PMMA 20), respectively. The batch compositions of porcelain samples are given in Table 1. Then, the mixed powders were uniaxially pressed to form bar-shaped specimens $(3 \times 4 \times 30 \mathrm{~mm})$ at $92 \mathrm{MPa}$ and disc specimens with a diameter of $35 \mathrm{~mm}$ at $82 \mathrm{MPa}$. After that, the specimens were sintered in an electric furnace at four different temperatures (1000, 1100, 1200 and $1300{ }^{\circ} \mathrm{C}$ ) with a heating rate of $5^{\circ} \mathrm{C} \cdot \mathrm{min}^{-1}$ and a dwell time of $1 \mathrm{~h}$ at maximum temperature. A schematic diagram of the experimental procedure is shown in Figure 1.

The Archimedes method was employed to determine the bulk density, water absorption and porosity (apparent, i.e. open, porosity) of the sintered samples. The three-point bending strength at room temperature was determined using a universal testing machine (Instron model UTM 55R4502) with a span of $20 \mathrm{~mm}$ and a crosshead speed of $0.5 \mathrm{~mm} \cdot \mathrm{min}^{-1}$. Phase analysis of samples was conducted through X-ray diffraction (XRD; PANalytical X'pert pro) with $40 \mathrm{kV}, 30 \mathrm{~mA}$, $\mathrm{CuK} \alpha$ radiation. The sample was scanned in a diffraction angle range of $10^{\circ}$ to $90^{\circ}$ with a step size of 0.04 and time per step $1 \mathrm{~s}$. The microstructure of samples was observed using a scanning electron microscope (FESEM; HITACHI, SU5000). Mercury intrusion porosimetry (Autopore V9600, Micromeritics) was used to study the pore size and pore size distribution. Thermal conductivity was measured using a thermal conductivity analyser (TPS2500S, Hot Disk) at room temperature. Samples were prepared in the disc shapes with $35 \mathrm{~mm}$ diameter and thickness of approximately $5 \mathrm{~mm}$.

\section{RESULTS AND DISCUSSION}

\section{Raw material characterization}

The chemical analysis of raw materials used for this study is given in Table 2. From the results, it was found that kaolin mainly consisted of $\mathrm{SiO}_{2}(47.5 \%)$ and $\mathrm{Al}_{2} \mathrm{O}_{3}$ $(35.9 \%)$ with a small amount of $\mathrm{Fe}_{2} \mathrm{O}_{3}(1.2 \%), \mathrm{K}_{2} \mathrm{O}$ $(1.8 \%), \mathrm{MgO}(0.1 \%)$, etc. The quartz contained pure $\mathrm{SiO}_{2}, 99.4 \%$. Generally, quartz is an inert filler providing high strength to sintered specimens $[9,25]$. The main components of potassium feldspar were $\mathrm{SiO}_{2}$ (64.7\%), $\mathrm{Al}_{2} \mathrm{O}_{3}(16.1 \%)$ and $\mathrm{K}_{2} \mathrm{O}(15.6 \%)$. Due to its high alkali contents, potassium feldspar acted as a fluxing agent, promoting a liquid phase at low temperature [3]. 
Table 2. Chemical composition of raw materials used in this study.

\begin{tabular}{cccc}
\hline \multirow{2}{*}{$\begin{array}{c}\text { Component } \\
\text { (Oxide, wt. \%) }\end{array}$} & \multicolumn{3}{c}{ Raw materials (wt. \%) } \\
\cline { 2 - 4 } & Kaolin & Quartz & K-feldspar \\
\hline $\mathrm{SiO}_{2}$ & 47.49 & 99.40 & 64.65 \\
$\mathrm{Al}_{2} \mathrm{O}_{3}$ & 35.85 & 0.05 & 16.11 \\
$\mathrm{Na}_{2} \mathrm{O}$ & 0.03 & 0.02 & 1.15 \\
$\mathrm{MgO}$ & 0.10 & 0.05 & 0.06 \\
$\mathrm{Fe}_{2} \mathrm{O}_{3}$ & 1.18 & 0.02 & 0.26 \\
$\mathrm{~K}_{2} \mathrm{O}$ & 1.78 & 0.02 & 15.55 \\
$\mathrm{P}_{2} \mathrm{O}_{5}$ & 0.04 & - & 0.34 \\
$\mathrm{SO}_{3}$ & 0.04 & 0.01 & 0.13 \\
$\mathrm{CaO}_{\mathrm{TiO}}$ & 0.02 & 0.13 & 0.79 \\
$\mathrm{MnO}_{2}$ & 0.06 & - & 0.04 \\
L.O.I $(\%)$ & 0.05 & - & 0.01 \\
& 12.86 & 0.22 & 0.53 \\
\hline
\end{tabular}

\section{Green porcelain samples}

Figure 2 shows the variation of green density values as a function of a pore foaming agent content. The low density of green samples was due to the lower density of PMMA $\left(1.19 \mathrm{~g} \cdot \mathrm{cm}^{-3}\right)$. The green densities of the porcelain samples were in the range of $1.75-1.54 \mathrm{~g} \cdot \mathrm{cm}^{-3}$.

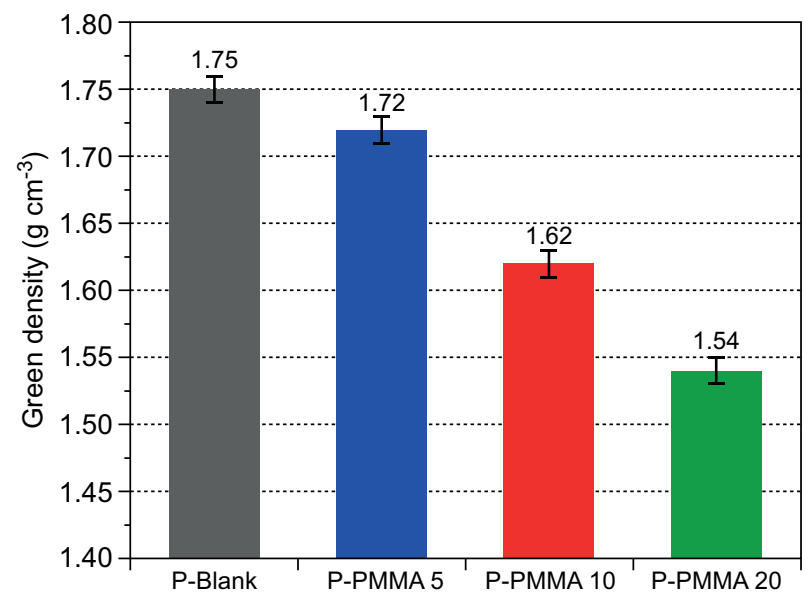

Figure 2. Green density of samples.

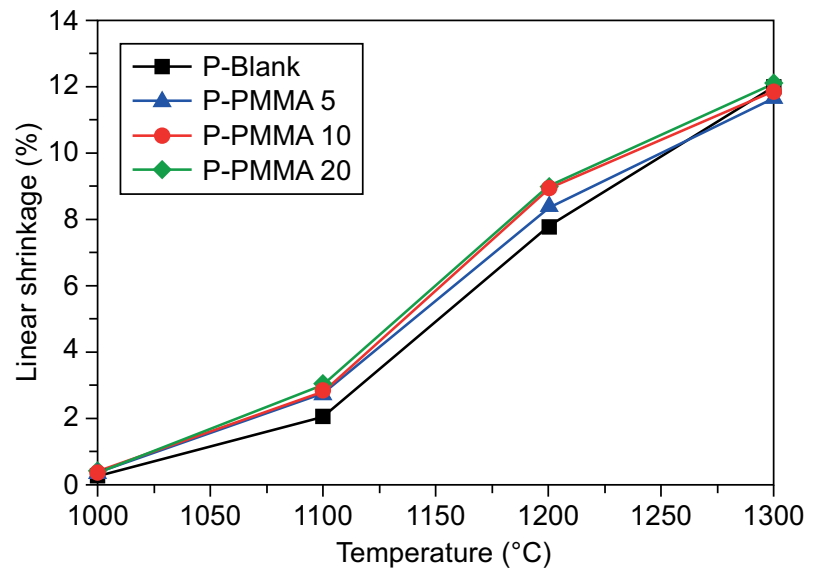

a) linear shrinkage
Considering a standard porcelain sample without PMMA addition (P-Blank), the green density value $\left(1.75 \mathrm{~g} \cdot \mathrm{cm}^{-3}\right)$ is comparable to that obtained from other porcelain compositions in the range of $1.8-2.0 \mathrm{~g} \cdot \mathrm{cm}^{-3}$ [26].

\section{Effect of PMMA addition on the densification characteristics and mechanical and thermal properties of sintered porcelain samples}

The porosity of the porcelain samples can be controlled by adding PMMA with contents in the range 0 - 20 wt. \%. Therefore, variations of linear shrinkage, bulk density, porosity and water absorption can be observed after firing to different temperatures. The linear shrinkage of the porcelain sample without (P-Blank) and with PMMA additions (P-PMMA) had a similar tendency as shown in Figure 3a. The linear shrinkage of samples continuously increased with an increase in temperature and reached the maximum value $(11.7$ - $12.2 \%)$ at $1300{ }^{\circ} \mathrm{C}$. The variation of bulk density for all porcelain samples is similar to their linear shrinkage as exhibited in Figure 3b. The bulk density for P-Blank sample significantly increased with a progressive rise in temperature and achieved a value of $2.41 \mathrm{~g} \cdot \mathrm{cm}^{-3}$ at $1300{ }^{\circ} \mathrm{C}$, which is consistent with that of typical porcelain-like bodies, $2.3-2.5 \mathrm{~g} \cdot \mathrm{cm}^{-3}[4,18,20,27]$. In addition, the incorporation of PMMA into porcelain bodies (P-PMMA) led to a decrease in the bulk density values due to the high level of porosity generation after the burnout of the organic particles during the firing process [5]. As can be seen in Figure 3c, the apparent porosity increased with an increment of PMMA. At $1300{ }^{\circ} \mathrm{C}$, the sample without PMMA (P-Blank) had the lowest apparent porosity of $0.2 \%$. In contrast, the porosity increased up to $17.2 \%$ when adding $20 \mathrm{wt}$. \% of PMMA (P-PMMA 20). The results indicate that this pore foaming agent can generate open porosity in the fired porcelain bodies [5]. Considering the water absorption (Figure 3d), these values tended to decrease with

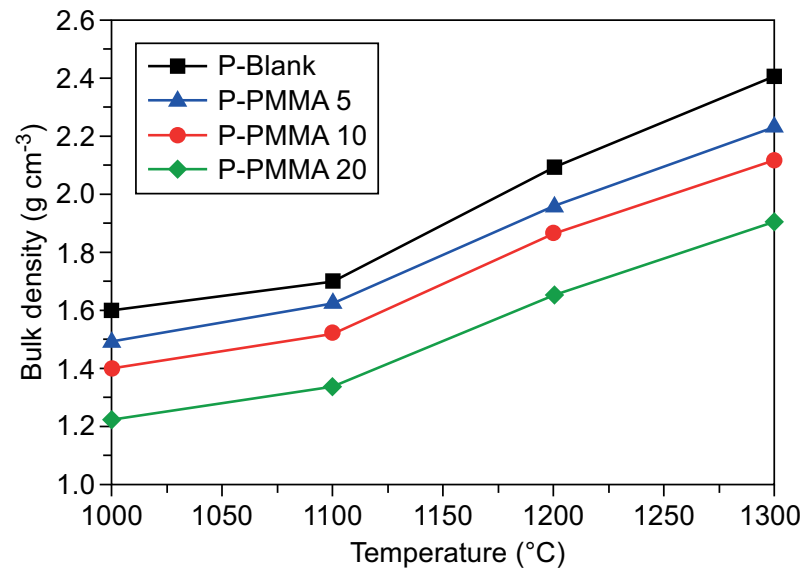

b) bulk density

Figure 3. Densification characteristics of porcelain samples after sintering at temperatures in the range 1000 to $1300{ }^{\circ} \mathrm{C}$ : a) linear shrinkage, b) bulk density. (Continue on next page) 


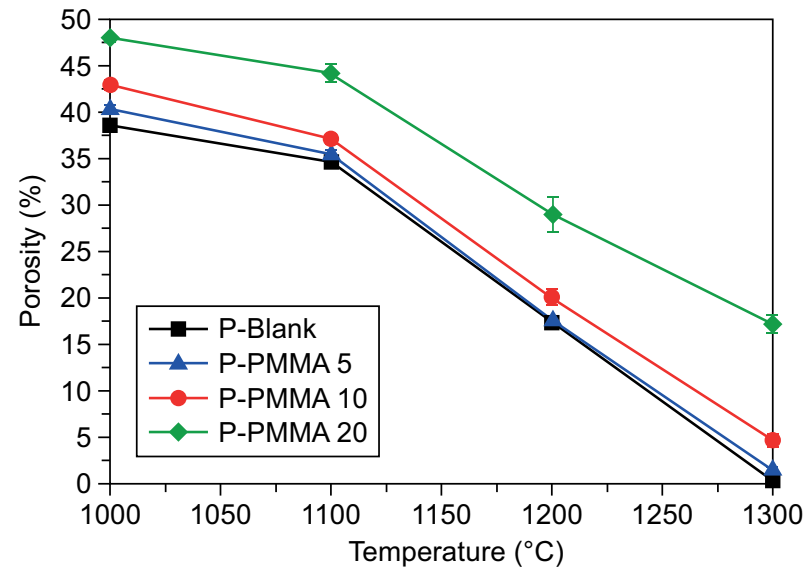

c) apparent porosity

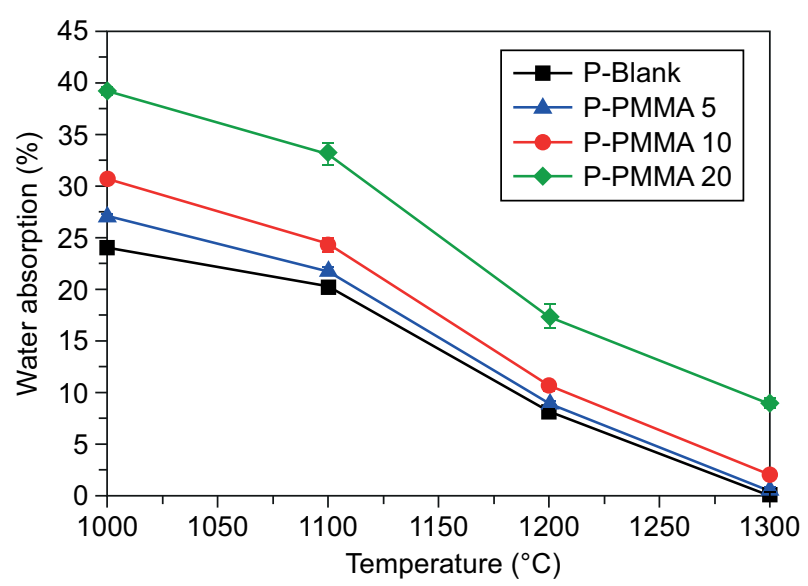

d) water absorption

Figure 3. Densification characteristics of porcelain samples after sintering at temperatures in the range 1000 to $1300{ }^{\circ} \mathrm{C}$ : c) apparent porosity, d) water absorption.

increasing temperatures due to the reduction of apparent porosity through a liquid phase formation during the firing process. At the highest temperature, the water absorption of P-Blank and P-PMMA 5 samples was close to zero (i.e., $0.1-0.6 \%$ ), while the addition of PMMA 10 - 20 wt. $\%$ increased the water absorption values to more than $2 \%$.

Figure 4 displays the flexural strength of sintered porcelain samples with and without PMMA addition. The sample without PMMA (P-Blank) showed an increase in strength with firing temperature and reached the highest value $(77 \mathrm{MPa})$ at $1300{ }^{\circ} \mathrm{C}$. The addition of PMMA caused a lower strength of porcelain samples, $36-56 \mathrm{MPa}$. It is well known that a high level of porosity resulted in the reduction of mechanical properties [5]. In this case, the densification of porcelain consisted of two steps including PMMA decomposition and liquid phase sintering process as shown in Figure 5. Initially, the PMMA particles were completely decomposed above $500{ }^{\circ} \mathrm{C}$ [5], creating porosity in the ceramic bodies. Then, the densification of porcelain involving a liquid phase sintering process initially occurred at around $900-1000^{\circ} \mathrm{C}$. A liquid phase began to form, surrounding the particles and generating a process-driving capillary underpressure (capillary suction) at the contact points, leading to shrinkage and densification (porosity reduction). Towards the end of the intermediate stage of sintering, at around $1180{ }^{\circ} \mathrm{C}$, pores began to close

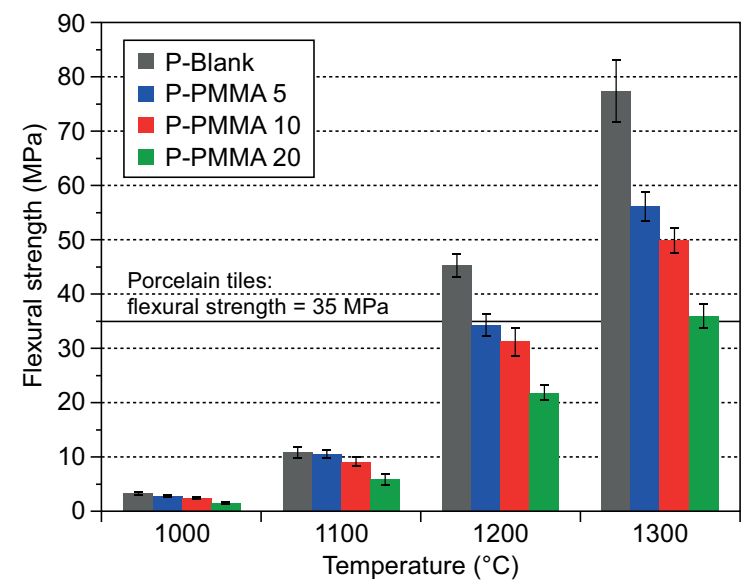

Figure 4. Flexural strength of sintered porcelain samples with and without PMMA addition sintered at temperatures in the range 1000 to $1300{ }^{\circ} \mathrm{C}$.

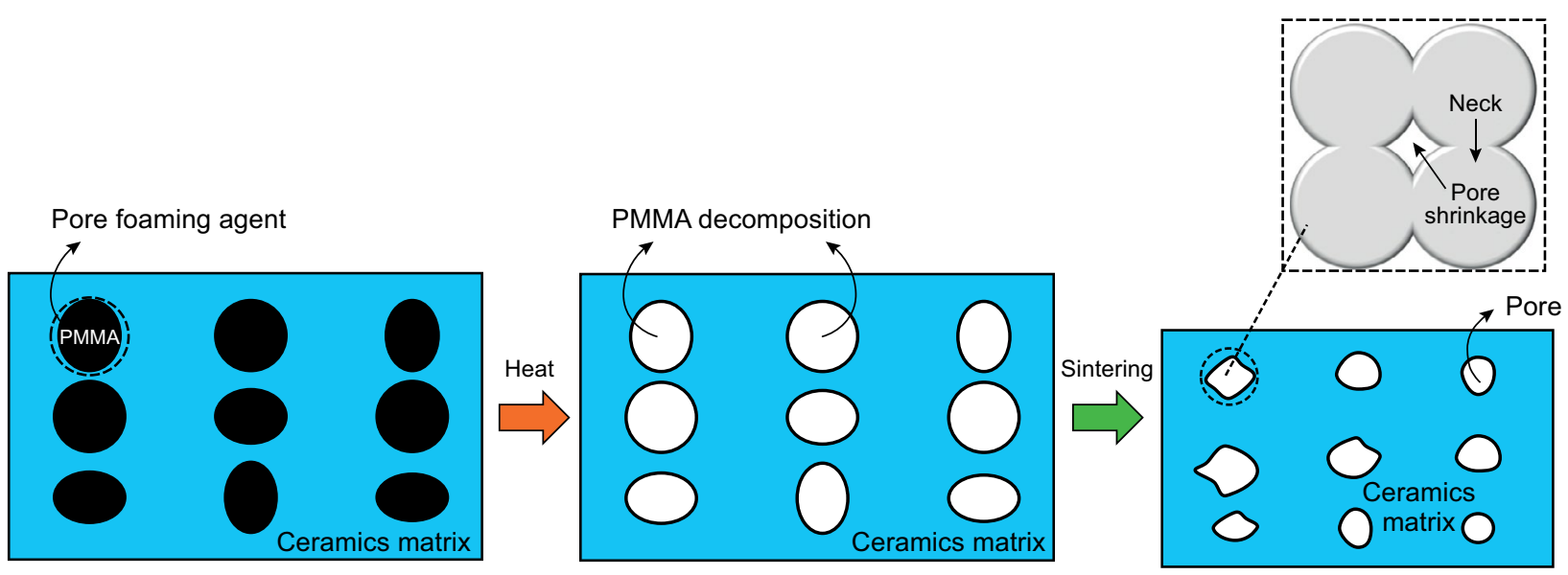

Figure 5. Schematic of porous porcelain fabrication using pore foaming agent. 


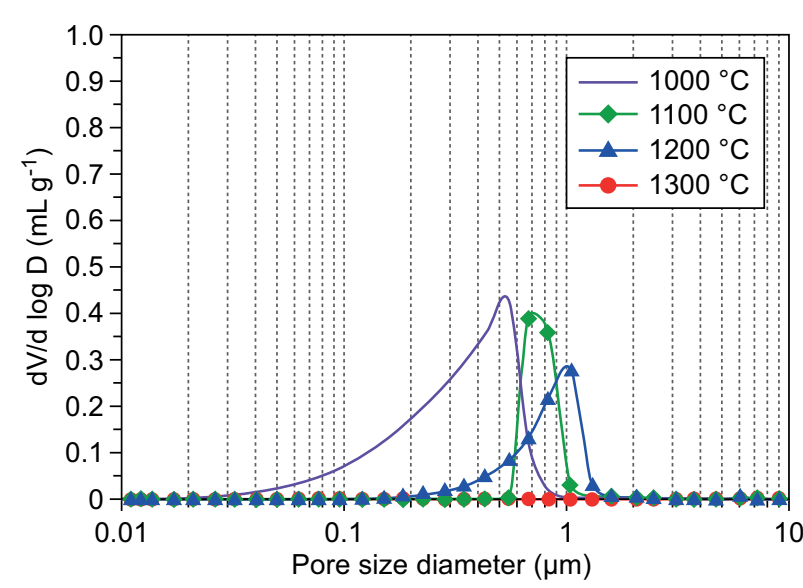

a) P-blank

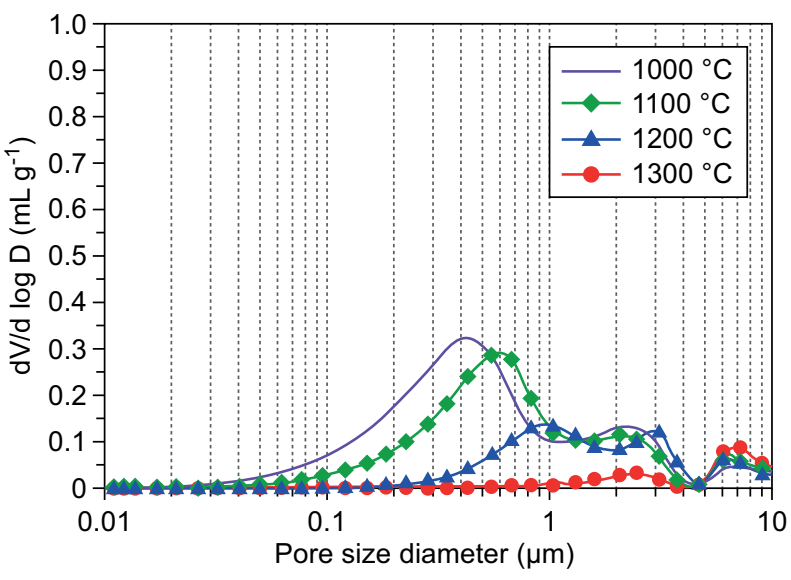

c) P-PMMA 10

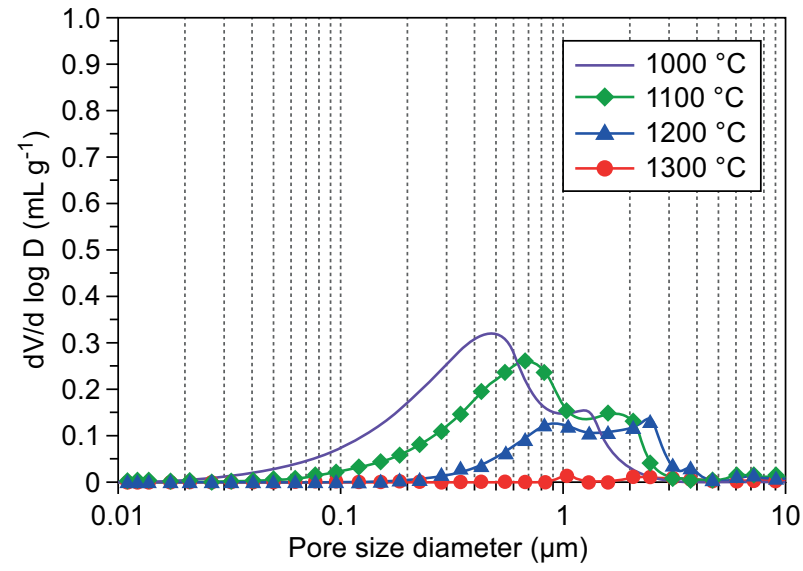

b) P-PMMA 5

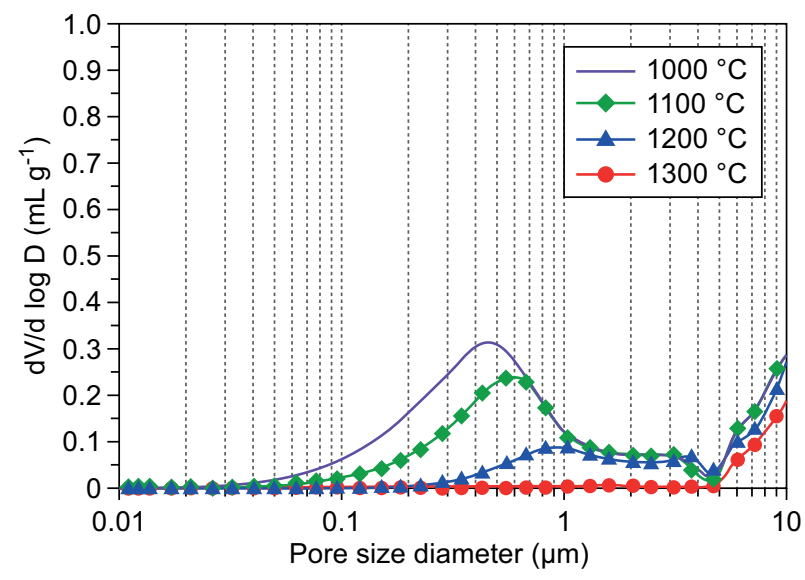

d) P-PMMA 20

Figure 6. Pore size distribution (Mercury Intrusion Porosimetry) of sintered samples at 1000 to $1300{ }^{\circ} \mathrm{C}$ : a) P-blank, b) P-PMMA 5, c) P-PMMA 10 and d) P-PMMA 20.

because interpore connections were eliminated. In the final stage (above $1200{ }^{\circ} \mathrm{C}$ ), the liquid phase flow was terminated, and closed gas-filled pore remained in the ceramic bodies $[28,29]$. The complete densification of porcelain samples during the three sintering stages was hindered by the porosity generated from PMMA decomposition. This caused the decrease in bulk density and mechanical properties.

From the results, it can be seen that the strength values of porous porcelain samples prepared by adding PMMA 5 - 20 wt. \% sintered at $1300{ }^{\circ} \mathrm{C}$ is higher than the minimum strength values (35 MPa) of the ISO 13006 standard for ceramic tiles $[4,27]$. Thus, it is possible to use this type of porcelain for ceramic tiles in order to enhance the thermal resistance of building materials.

In order to investigate the pore evolution created by pore foaming agent (PMMA), the pore size and its distribution as well as the microstructure are considered. The pore size, pore size distribution and open porosity of sintered porcelain samples prepared with and without PMMA determined by mercury intrusion porosity (MIP) are presented in Table 3 and Figure 6. In Figure 6, the amount of mercury intrusion into the pores of the
Table 3. Pore characterization obtained from mercury intrusion porosimetry of sintered ceramics prepared with PMMA (45 - $250 \mu \mathrm{m})$.

\begin{tabular}{lccc}
\hline Samples & $\begin{array}{c}T \\
\left({ }^{\circ} \mathrm{C}\right)\end{array}$ & $\begin{array}{c}\text { Average pore } \\
\text { diameter }(\mu \mathrm{m})\end{array}$ & $\begin{array}{c}\text { Open } \\
\text { porosity }(\%)\end{array}$ \\
\hline \multirow{4}{*}{ P-Blank } & 1000 & 0.25 & 35.4 \\
& 1100 & 1.00 & 14.1 \\
& 1200 & 0.84 & 18.4 \\
& 1300 & 16.08 & 1.0 \\
\hline \multirow{4}{*}{ P-PMMA 5 } & 1000 & 0.29 & 37.7 \\
& 1100 & 0.63 & 38.2 \\
& 1200 & 1.27 & 23.1 \\
& 1300 & 5.80 & 7.4 \\
\hline \multirow{4}{*}{ P-PMMA 10 } & 1100 & 0.38 & 44.8 \\
& 1200 & 0.55 & 37.8 \\
& 1300 & 1.42 & 25.5 \\
& 1000 & 15.90 & 31.0 \\
\hline \multirow{4}{*}{ P-PMMA 20 } & 1100 & 0.59 & 54.2 \\
& 1200 & 0.89 & 46.0 \\
& 1300 & 2.98 & 38.2 \\
\hline
\end{tabular}

Ceramics - Silikáty 64 (2) 164-171 (2020) 
porcelain samples reduced with an increase in firing temperature. Consequently, a decrease in the open porosity was obtained. The results of the open porosity determined by mercury intrusion (Table 3) were in good

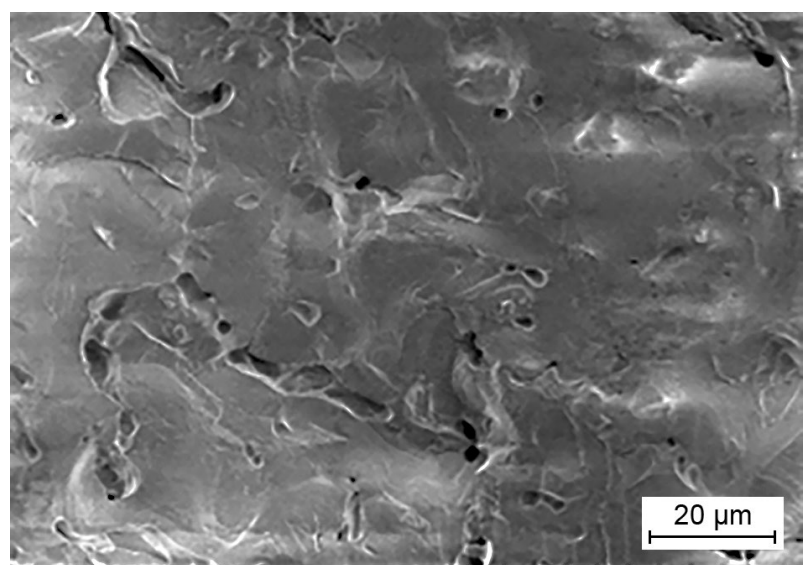

a) P-blank

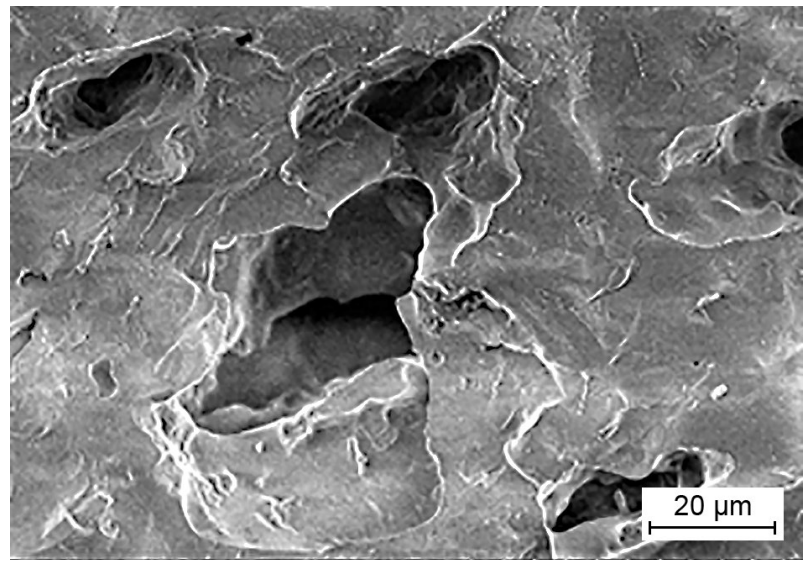

c) P-PMMA 10 agreement with the apparent porosity evaluated by the Archimedes method as reported in Figure 2. Gultekin et al. suggested that the reduction of open porosity during the initial and intermediate stage of sintering contributed

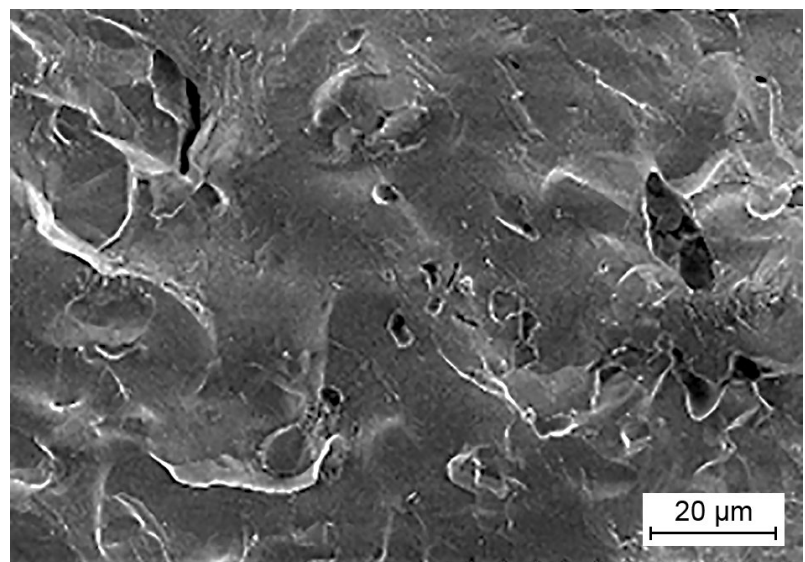

b) P-PMMA 5

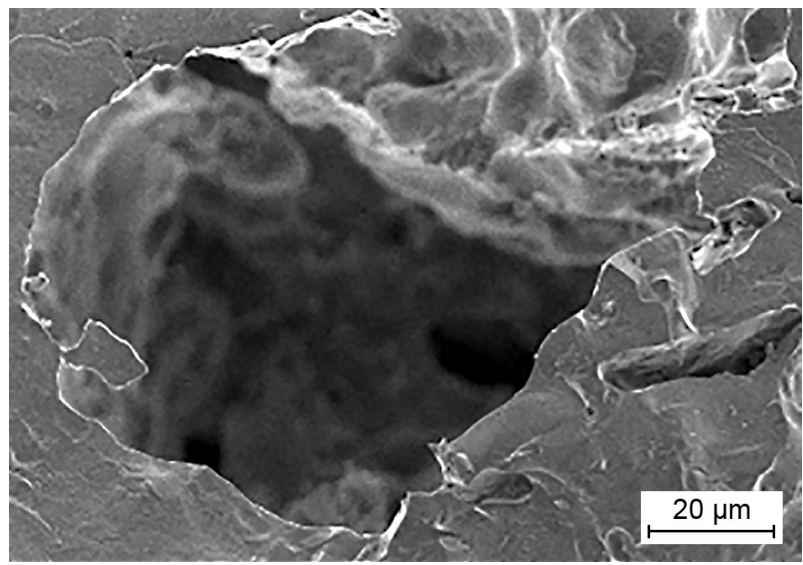

d) P-PMMA 20

Figure 7. SEM micrographs of porcelain samples (fracture surfaces) after sintering at $1300{ }^{\circ} \mathrm{C}$ : a) P-blank, b) P-PMMA 5, c) P-PMMA 10 and d) P-PMMA 20.

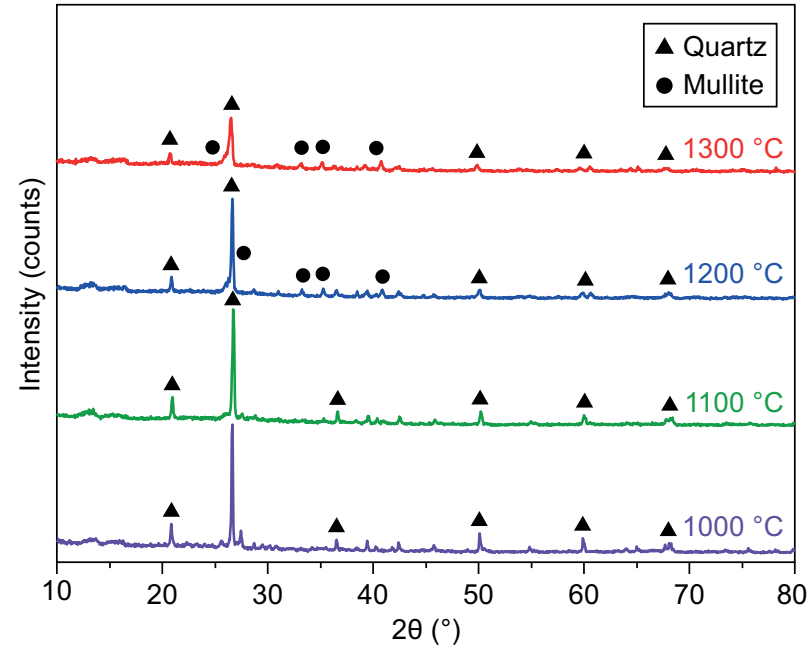

a) without PMMA

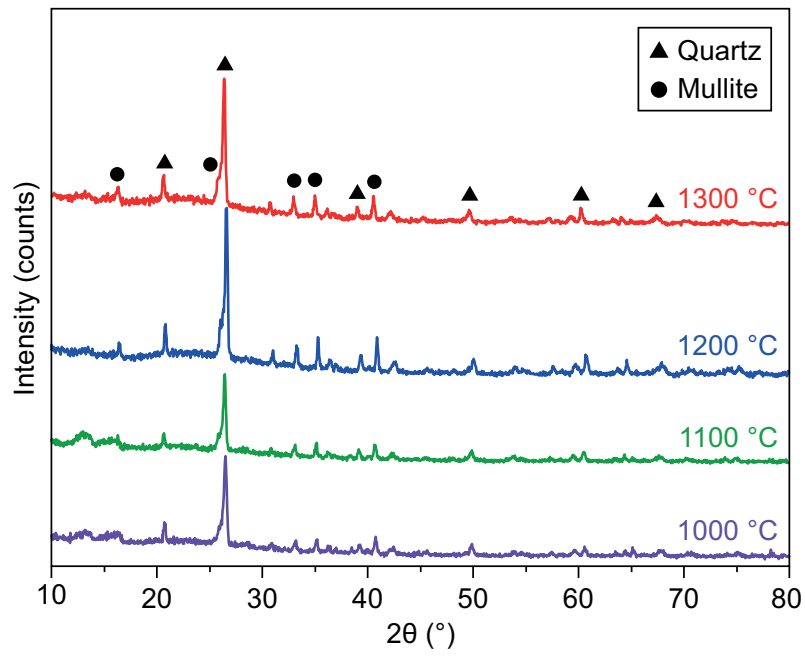

b) with PMMA

Figure 8. XRD patterns of sintered porcelain samples: a) without PMMA addition (P-blank) sintered at different temperatures, b) with PMMA contents of 0 - 20 wt. \% sintered at $1300{ }^{\circ} \mathrm{C}$. 
to the elimination of smaller pores, and, consequently, the development of larger pores could have happened due to particle rearrangement [28]. Thus, the larger average pore diameter was observed with the porcelain samples fired at the highest temperature of $1300^{\circ} \mathrm{C}$. Furthermore, the introduction of PMMA led to the growth of the pore diameter. As can be seen in Figure 6, the equivalent pore diameter curves shifts towards higher values when more PMMA was added to the porcelain bodies. In addition, a broadening of the peaks can be observed in the porcelain samples by adding PMMA (P-PMMA). The reason is that mercury intrusion porosimetry probes the pore throats (not the pore cavities) [21] and these are naturally larger when for a higher content of pore forming agent is used.

Figure 7 shows the SEM micrographs of porcelain samples with various porosity levels as a result of the addition of PMMA in the range 0 - $20 \mathrm{wt} . \%$ sintered at $1300{ }^{\circ} \mathrm{C}$. A dense structure with a low level of porosity and uniform micro-pore distribution was observed in the sample P-Blank (without PMMA, Figure 7a), while the formation of larger pores started with the addition 5 wt. $\%$ and 10 wt. $\%$ of PMMA (Figures $7 b$ and c). The largest pores $(>50 \mu \mathrm{m})$ can be detected with the addition of 20 wt. $\%$ of PMMA.

Figure 8 shows the XRD patterns of the porcelain samples with different PMMA content (0 - 20 wt. \%). At a low sintering temperature $\left(1000-1100{ }^{\circ} \mathrm{C}\right)$, the only crystalline phase is quartz (JCPDS, number 46-1045), whereas the development of mullite (Mullite, JCPDS No. 73-1389) was found at a higher sintering temperature $\left(1200-1300{ }^{\circ} \mathrm{C}\right)$ as shown in Figure 8a. Indeed, mullite typically occurs at a temperature of around $1200{ }^{\circ} \mathrm{C}$ [2]. In addition, the incorporation of pore former (PMMA) did not hinder the formation of mullite at a high temperature. As a result, the porous porcelain samples prepared in this study can maintain the suitable mechanical strength that was higher than the minimum strength values $(35 \mathrm{MPa})$ of the ISO 13006 standard for

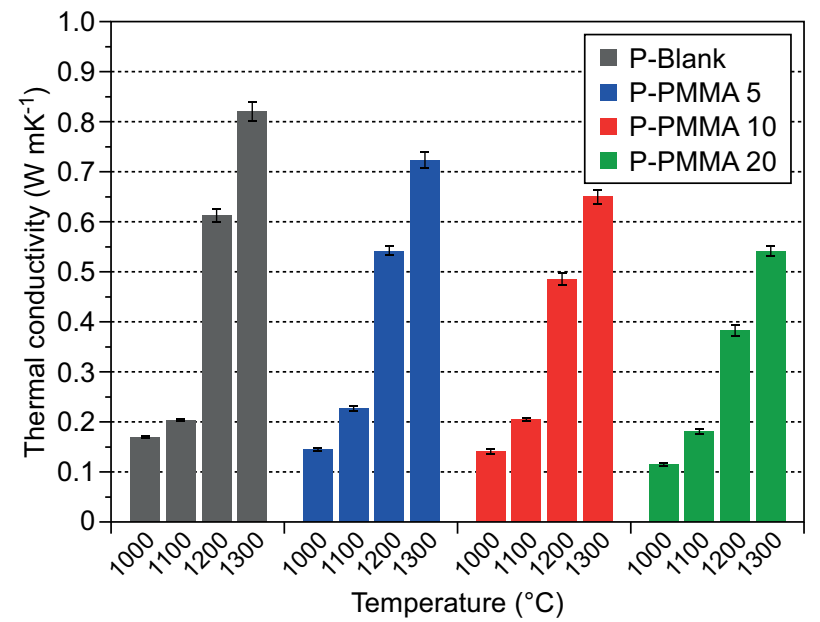

Figure 9. Thermal conductivity of porous ceramic prepared with and without PMMA. porcelain tiles, as demonstrated in Figure 4.

Figure 9 shows the thermal conductivity of porous porcelain as a function of the expected, an increase in the sintering temperature increases the thermal conductivity of the ceramic samples. Moreover, the thermal conductivity significantly decreased with increasing porosity levels. Even at $1300{ }^{\circ} \mathrm{C}$, the reduction of thermal conductivity can be clearly observed. Thermal conductivity decreased from $0.82 \mathrm{~W} \cdot \mathrm{m}^{-1} \cdot \mathrm{K}^{-1}$ for dense porcelain sample (P-Blank) to $0.72,0.65$ and $0.54 \mathrm{~W} \cdot \mathrm{m}^{-1} \cdot \mathrm{K}^{-1}$ for the porous porcelain samples made by adding 5,10 and 20 wt. \% PMMA, respectively. A similar behaviour in the reduction of thermal conductivity was observed by Novais at al. [5]. They created the porosity using polymer particles (polypropylene and PMMA) in porcelain specimens and found that the specimens with both pore formers added had a lower thermal conductivity as compared to the original porcelain. In the present work, the addition of $20 \mathrm{wt} \%$ PMMA in porcelain samples sintered at $1300{ }^{\circ} \mathrm{C}$ reduced the thermal conductivity by up to $34 \%$ while maintaining acceptable flexural strength values $(\sim 36 \mathrm{MPa})$.

It can be concluded that porous porcelain tiles with high mechanical strength and low thermal conductivity can be prepared using PMMA as a performing agent in order to improve the thermal resistance of building materials.

\section{CONCLUSIONS}

Porous porcelain tiles were successfully prepared by adding PMMA with a size of $45-250 \mu \mathrm{m}$ in the proportion of 5 - $20 \mathrm{wt}$. \% for improving the thermal resistance. The incorporation of PMMA to generate pore structures in porcelain bodies resulted in a decrease of the density values, while the apparent porosity and water absorption increased with increasing PMMA content. The increase in the porosity into the porcelain bodies promoted the reduction of thermal conductivity while maintaining acceptable mechanical strength $(>35 \mathrm{MPa})$ according to the ISO 13006 standard. The addition of 5 - 20 wt. \% PMMA in porcelain samples sintered at $1300{ }^{\circ} \mathrm{C}$ reduced the thermal conductivity by $12-34 \%$, while the flexural strength values are in the range of 36 - $56 \mathrm{MPa}$. Obviously, the thermal conductivity reduction is tantamount with an increase in the thermal resistance of ceramic building materials, i.e. a reduction of heat transfer from the outside into buildings and vice versa, which may generally contribute to energy saving.

\section{Acknowledgements}

This research was financially supported by the National Metal and Materials Technology Center, Thailand (Project No. MT-B-61-CER-07-314-I). 


\section{REFERENCES}

1. ISO 13006: Ceramic Tiles - Definitions, Classification, Characteristics and Marking. International Organization for Standardization, 1998.

2. Romero M., Perez J.M. (2015): Relation between the microstructure and technological properties of porcelain stoneware. A review. Materiales De Construccion, 65, 1-15. doi: 10.3989/mc.2015.05915

3. Dondi M., Raimondo M., Zanelli C. (2014): Clays and bodies for ceramic tiles reappraisal and technological classification. Applied Clay Science, 96, 91-109. doi: 10.1016/j.clay.2014.01.013

4. Vichaphund S., Sonton K., Wonglom T., Rodchom M., Atong D. (2016): Utilization of basalt as a raw material for clay ceramic production. Ceramics-Silikaty, 60(2), 72-76. doi: $10.13168 / \mathrm{cs} .2016 .0011$

5. Novais R.M., Seabra M.P., Labrincha J.A. (2014): Ceramic tiles with controlled porosity and low thermal conductivity by using pore-forming agents. Ceramics International, 40, 11637-11648. doi:10.1016/j.ceramint.2014.03.163

6. Martin-Marquez J., Rincon J. M., Romero M. (2010): Effect of microstructure on mechanical properties of porcelain stoneware. Journal of the European Ceramic Society, 30(15), 3063-3069. doi: 10.1016/j.jeurcermsoc.2010.07.015

7. Rambaldi E., Pabst W., Gregorova E., Prete F., Bignozzi M. C. (2017): Elastic properties of porous porcelain stoneware tiles. Ceramics International, 43, 6919-6924. doi: 10.1016/j.ceramint.2017.02.114

8. Martin-Marquez J., Rincon J. M., Romero M. (2010): Mullite development on firing in porcelain stoneware bodies. Journal of the European Ceramic Society, 30(7), 1599-1607. doi: 10.1016/j.jeurcermsoc.2010.01.002

9. Zanelli C., Raimondo M., Dondi M. (2011): The vitreous phase of porcelain stoneware composition evolution during sintering and physical properties. Journal of NonCrystalline Solids, 357(16-17), 3251-3260. doi: 10.1016/j. jnoncrysol.2011.05.020

10. Fadaly E. E. (2013): Characterization of porcelain stoneware tiles based on solid ceramic wastes. International Journal of Science and Research, 4(1), 602-608.

11. Sanchez E., Sanz V., Canas E., Sales J., Kayaci K., Taskiran M. U., Anil U. E., Turk S. (2019): Revisiting pyroplastic deformation application for porcelain stoneware tile bodies. Journal of the European Ceramic Society, 39(2-3), 601-609. doi: 10.1016/j.jeurcermsoc.2018.09.032

12. da Silva A. L., Feltrin J., Dal Bo M., Bernardin A. M., Hotza D. (2014): Effect of reduction of thickness on microstructure and properties of porcelain stoneware tiles. Ceramics International, 43, 14693-14699. doi: 10.1016/j. ceramint.2014.05.150

13. Luz A. P., Ribeiro S. (2007): Use of glass waste as a raw material in porcelain stoneware tile mixtures. Ceramics International, 33, 761-765. doi: 10.1016/j.ceramint.2006. 01.001

14. Magagnin D., dos Santos C.M.F., Wanderlind A., Jiusti J., De Noni A. (2014): Effect of kaolinite illite and talc on the processing properties and mullite content of porcelain stoneware tiles. Materials Science and Engineering A, 618, 533-539. doi:10.1016/j.msea.2014.09.049

15. Owoeye S. S., Toludare T. S., Isinkaye O. E., Kingsley U. (2019): Influence of waste glasses on the physico-mecha- nical behavior of porcelain ceramics. Boletín de la Sociedad Española de Cerámica y Vidrio, 58(2), 77-84. doi: 10.1016/j.bsecv.2018.07.002

16. Dong W., Bao Q., Zhou J., Zhao T., Liu K., Hu Z. (2017): Preparation of porcelain building tiles using $\mathrm{K}_{2} \mathrm{O}-\mathrm{Na}_{2} \mathrm{O}$ feldspar flux as a modifier agent of low-temperature firing. Journal of the Ceramic Society of Japan, 125, 690-694. doi: $10.2109 /$ jcersj 2.16327

17. Garcia O.M., Hernandez R.L., Lara A. A., Gil-Vazquez J. L., Garcia J. A. (2014): Increasing bending strength of porcelain stoneware via pseudoboehmite additions. Journal of Ceramics, 1-7. doi: 10.1155/2014/270689

18. Serra M.F., Conconi M.S., Suarez G., Aglietti E.F., Rendtorff N.M. (2015): Volcanic ash as flux in clay based triaxial ceramic materials, effect of the firing temperature in phases and mechanical properties. Ceramics International, 41(5), 6169-6177. doi: 10.1016/j.ceramint.2014.12.123

19. da Silva A. L., Dondi M., Raimondo M., Hotza, D. (2018): Photocatalytic ceramic tiles: Challenges and technological solutions. Journal of the American Ceramic Society, 38(4), 1002-1017, doi: 10.1016/j.jeurceramsoc.2017.11.039

20. Rambaldi E., Prete F., Bignozzi M. C. (2015): Acoustic and thermal performances of ceramic tiles and tiling systems. Ceramics International, 41, 7252-7260. doi: 10.1016/j. ceramint.2015.03.032

21. Gregorová E., Živcová Z., Pabst W. (2009): Starch as a pore-forming and body-forming agent in ceramic technology. Starch-Stärke, 61(9), 495-502. doi: 10.1002/star.200900138

22. Liu J., Li Y., Li Y., Sang S., Li S. (2016): Effects of pore structure on thermal conductivity and strength of alumina porous ceramics using carbon black as pore-forming agent. Ceramics International, 42(7), 8221-8228. doi: 10.1016/j. ceramint.2016.02.032

23. Gregorová E., Pabst W. (2007): Porous ceramics prepared using poppy seed as a pore-forming agent. Ceramics International, 33, 1385-1388. doi: 10.1016/j.ceramint.2006.05. 019

24. Novais R. M., Seabra M. P., Labrincha J. A. (2015): Wood waste incorporation for lightweight porcelain stoneware tiles with tailored thermal conductivity. Journal of Cleaner Production, 90, 66-72. doi: 10.1016/j.jclepro.2014.11.045

25. Galos K. (2011): Composition and ceramic properties of ball clays for porcelain stoneware tiles manufacture in Poland. Applied clay science, 51(1), 74-85. doi: 10.1016/j. clay.2010.11.004

26. Pérez J.M., Rincón J.M., Romero M. (2012): Effect of moulding pressure on microstructure and technological properties of porcelain stoneware. Ceramics International, 38(1), 317-325. doi: 10.1016/j.ceramint.2011.07.009

27. Ke S., Wang Y., Pan Z., Ning C., Zheng S. (2016): Recycling of polished tile waste as a main raw material in porcelain tiles. Journal of Cleaner Production, 115, 238-244. doi: 10.1016/j.jclepro.2015.12.064

28. Gültekin E. E., Topates G., Kurama S. (2017): The effects of sintering temperature on phase and pore evolution in porcelain tiles. Ceramics International, 43(14), 11511-11515. doi: 10.1016/j.ceramint.2017.06.024

29. Amorós J. L., Orts M. J., García-Ten J., Gozalbo A., Sánchez E. (2007): Effect of the green porous texture on porcelain tile properties. Journal of the European Ceramic Society, 27, 2295-2301. doi: 10.1016/j.jeurceramsoc.2006.07.005 